\title{
MiR-214-3p Promotes Proliferation and Inhibits Estradiol Synthesis In Porcine Granulosa Cells
}

\section{Shengjie Shi}

Northwest Agriculture and Forestry University

Xiaoge Zhou

Northwest Agriculture and Forestry University

Jingjing Li

Northwest Agriculture and Forestry University

Lutong Zhang

Northwest Agriculture and Forestry University

Yamei Hu

Northwest Agriculture and Forestry University

Yankun Li

Northwest Agriculture and Forestry University

\section{Gongshe Yang}

Northwest Agriculture and Forestry University

Guiyan Chu ( $\sim$ guiyanchu@nwafu.edu.cn )

Northwest Agriculture and Forestry University https://orcid.org/0000-0001-9449-3894

\section{Research}

Keywords: miR-214-3p, granulosa cells, proliferation, estradiol synthesis

Posted Date: April 1st, 2020

DOI: https://doi.org/10.21203/rs.3.rs-20342/v1

License: (c) (1) This work is licensed under a Creative Commons Attribution 4.0 International License. Read Full License

Version of Record: A version of this preprint was published on September 14th, 2020. See the published version at https://doi.org/10.1186/s40104-020-00500-y. 


\section{Abstract}

Background: Granulosa cells proliferation and estradiol synthesis significantly affect follicular development. The miR-214-3p expression in the ovarian tissues of high-yielding sows is higher than that in low-yielding sows, indicating that miR-214-3p may be involved in sow fertility. However, the functions and mechanisms of miR-214-3p on granulosa cells are unclear. In this study, miR-214-3p was transfected into porcine ovarian granulosa cells to investigate its functions in terms of proliferation and estradiol synthesis via flow cytometry, CCK-8 assay, EdU staining, ElisA, Real-Time PCR, and Western blot analyses. We also identified the targets of miR-214-3p via Luciferase Reporter Assay.

Results: Our findings revealed that miR-214-3p promotes proliferation and inhibits estradiol synthesis in porcine granulosa cells. We also found that miR-214-3p up-regulates the expression of cell cycle genes including Cell cycle protein B (Cyclin B), Cell cycle protein D (Cyclin D), Cell cycle protein E (Cyclin E), and Cyclin-dependent kinase 4 (CDK4) at the transcription and translation levels, while downregulating the mRNA and protein levels of cytochrome P450 family 11 subfamily A member 1 (CYP11A1), cytochrome P450 family 19 subfamily A member 1 (CYP19A1), and steroidogenic acute regulatory protein (StAR) (i.e., the key enzymes in estradiol synthesis). On-line prediction, bioinformatics analysis, a luciferase reporter assay, RT-qPCR, and Western blot results showed that the target genes of miR-214-3p in proliferation and estradiol synthesis are Mfn2 and NR5A1, respectively.

Conclusions: Our findings suggest that miR-214-3p plays an important role in the functional regulation of porcine granulosa cells and therefore may be a target gene for regulating follicular development.

\section{Introduction}

Granulosa cells, as the largest cell population in mature follicles, are the body's primary source of estrogen and progesterone. The morphology and function of granulosa cells is altered by primordial follicle growth initiation, proliferation, differentiation, atresia, ovulation, and luteum formation. Granulosa cells also can regulate the development of oocytes and follicles by secreting cytokines and hormones, which further affects female reproductive performance $(1,2)$. Thus, the proliferation and hormone secretion of granulosa cells are closely related to the growth and development of follicles (3).

Follicle development in the ovary requires recruitment, selection, and dominance processes. The original follicles gradually develop into primary follicles, secondary follicles, antral follicles, and preovulatory follicles (4) accompanied by the transformation of granulosa cells from a monolayer to a cubic shape of 2-3 layers, followed by multiple layers and cavities (5). Follicle growth is, to this effect, inseparable from granulosa cell (GC) proliferation (6).

There are three types of estrogen, the most active of which is estradiol (7). During the synthesis of estradiol, FSH (follicle-stimulating hormone) receptors produced by GCs bind to FSH from the pituitary gland, which activates the FSH signaling pathway and increases the expression of related enzymes (e.g., CYP11A1, a cytochrome P450) while promoting estradiol synthesis $(8,9)$. FSH can also interact with 
receptors in the surface membranes of GCs, activate adenylyl cyclase, and subsequently increase intracellular cAMP levels. The expression of aromatase (CYP19A1) corresponds to the increase of $E_{2}$ secretion. In addition, StAR can transport the cholesterol from the outer to the inner mitochondrial membrane, where it is converted to pregnenolone by CYP11A1. Estradiol promotes the formation of follicles and gonadotropin receptors in the ovary $(10,11)$, inhibits the apoptosis of GCs $(12)$, facilitates the formation of corpus luteum, and maintains the corpus luteum and regulates steroid synthesis, among other functions.

MicroRNA (miRNA) is a short (20-24nt) non-coding RNA, which mainly binds to the 3'UTR of the target gene's mRNA sequence to stimulate degradation of mRNA to regulate mRNA expression at the posttranscriptional level and inhibit its translation $(13,14)$. Many previous studies have demonstrated that miRNA regulates the biological function of GCs by its targets. For example, in mouse GCs, miRNA-746-3p targets steroidogenic factor-1 (SF-1) to regulate 17ß-estradiol synthesis (15). MiR-202-5p induces apoptosis in goat GCs by targeting TGF $\beta R 2$ (16). Another research proved that miR-1275 controls GCs apoptosis and estradiol synthesis by impairing LRH-1/CYP19A1 axis (17). However, certain phenotypes and mechanisms that other miRNAs regulate porcine ovarian GCs proliferation and estradiol synthesis yet merit further research.

MiR-214 is transcribed from Dynamin3 and forms a vertebrate-specific conserved cluster with miR-199 $(18,19)$. Research on miR-214-3p tends to center on oncology, skeletal muscle development, adipogenesis, and similar applications (20-22). Sequencing results from the ovarian tissue of Yorkshire pigs has shown that miR-214 expression significantly differs between large and small litter sizes (23). Studies have also shown that miR-214 may regulate steroids by targeting low-density lipoprotein receptor genes in rat GCs (24). We used Kyoto Encyclopedia of Genes and Genomes (KEGG) pathway and Gene Ontology (GO) analyses to find that miR-214-3p is enriched in the TGF-beta signaling pathway and mTOR signaling pathway, and further, is involved in the physiological processes of cell proliferation and estradiol synthesis. In short, the literature suggests that miR-214 is involved in the biological functions of GCs. However, the specific effects of miR-214 on GCs remain unclear and are worth further analysis.

In this study, we demonstrated that miR-214-3p can promote the proliferation of porcine ovarian GCs by targeting Mfn2 and can inhibit estradiol synthesis by targeting NR5A1 in the GCs. The results presented here may provide new insight into the mechanisms by which miR-214-3p regulates GCs biological functions.

\section{Materials And Methods}

\subsection{Granulosa cells isolation and culture}

Landrace ovaries $(n=20)$ from cyclic sows (Sus scrofa) were obtained immediately after slaughter, soaked in saline solution, and stored at $37^{\circ} \mathrm{C}$. The ovaries were shipped back to the laboratory within $2 \mathrm{~h}$ and were dissected and cleaned in thermostatic saline solution. The antral follicles (3-5 mm diameter) 
situated on the ovarian surface were punctured by needles to release the follicular fluid and flushed with culture medium DMEM/F12 containing 3\% BSA, 1 IU FSH (SHUSHENG, China), and 1 IU LH (SHUSHENG, China) (25). The culture medium with GCs and cumuluse oocyte complexes was filtered through a 70-mm cell strainer. The cumuluse oocyte complexes were filtered out and the filtrate with GCs was centrifuged at $1000 \times \mathrm{g}$ for $10 \mathrm{~min}$. The GCs were then suspended with DMEM/F12 containing $3 \% \mathrm{BSA}$, inoculated in a cell culture well, and cultured in a cell incubator with $5 \% \mathrm{CO}_{2}$ at $37^{\circ} \mathrm{C}(3)$.

\subsection{Transfection of miRNA agomir and antagomir}

An agomir is a type of specially labeled and chemically modified double-stranded microRNA which can regulate the biological function of a target gene by mimicking endogenous microRNA. An antagomir is a type of specially labeled and chemically modified single-stranded microRNA, designed based on the mature microRNA sequence, which can inhibit the expression of endogenous microRNA. The miR-214-3p agomir, antagomir, and respective nonspecific control (NC) materials used in this study were purchased from GenePharma (Shanghai, China) and were transfected into GCs with X-treme GENE HP DNA Transfection Reagent (Roche, Mannheim, Germany) at a final concentration of $50 \mathrm{nM}$ according to the manufacturer's protocol. The medium was changed once after $24 \mathrm{~h}$ of transfection (22).

\subsection{RNA isolation and quantitative real-time PCR}

Total RNA samples were isolated using Trizol (TakaRa, Otsu, Japan). The final concentrations were measured by NanoDrop 2000 (Thermo, Waltham, MA, USA). The cDNA was synthesized using a reverse transcription kit (TakaRa, Otsu, Japan). We used quantitative real-time PCR (RT-qPCR) for mRNA analysis. Every reaction was performed in triplicate with SYBR Premix (Vazyme, Nanjing, China) on a StepOne RealTime PCR Machine (ABI, Carlsbad, CA, USA) (26). The relative mRNA level was normalized to that of Gapdh and calculated using the $2^{-\Delta \Delta C t}$ algorithm. The primer sequences we used for the RT-qPCR are listed in Table 1.

\subsection{Western blot analysis}

The cell total protein was isolated using RIPA (Applygen Technologies Inc., Beijing, China). Protease inhibitor (CWBIO, Shanghai, China) was added into the RIPA at a ratio of 1:100. After adding RIPA to the cell culture plate, we collected the cells and centrifuged $(12,000 \mathrm{rpm})$ the material at $4{ }^{\circ} \mathrm{C}$ for $10 \mathrm{~min}(27)$. Protein concentrations were measured on a Thermo Scientific Pierce BCA protein assay kit (Thermo Fisher, USA) with $1 / 4$ volume of $5 \times$ loading buffer added to the supernatant. A total of $20 \mu \mathrm{L}$ of protein was blotted using $10 \%$ SDS-polyacrylamide gel, then transferred to a polyethylene difluoride (PVDF) membrane (CST, Boston, MA, USA). After blocking with $5 \%$ defatted milk for $2 \mathrm{~h}$, the membranes were incubated overnight at $4{ }^{\circ} \mathrm{C}$ with antibodies (1:1000) against StAR, CYP19A1, CYP11A1, Mfn2, NR5A1 (Abcam, Cambridge, UK) and against Cyclin B, Cyclin D, Cyclin E, CDK4 (Santa Cruz, TX, USA). The membrane HRP goat anti-mouse IgG, goat anti-rabbit IgG, and rabbit anti-goat IgG secondary antibodies (BOSTER, China) were diluted 1:3000 according to the instructions and incubated for $1 \mathrm{~h}$. Detection was performed using chemiluminescence Western blotting substrate (Santa Cruz, CA, USA) in Image Lab analysis software (Image Lab' ${ }^{\text {TM }}$, Bio-Rad, Berkeley, CA, USA). 


\subsection{Flow cytometry}

Porcine GCs were cultured in a 6-well culture plate at a density of $4 \times 10^{5}$ per well. The cells were treated with miR-214-3p-agomir or antagomir for $48 \mathrm{~h}$. The cells were digested with $0.25 \%$ trypsin and terminated with DMEM containing $10 \% \mathrm{FBS}$, then collected and fixed in cold $70 \%$ ethanol overnight at $4{ }^{\circ} \mathrm{C}(28)$. Afterwards, the cells were washed twice and stained with $50 \mathrm{mg} / \mathrm{mL}$ propidium iodide (PI) for 30 min. Finally, the cell cycles of the porcine subcutaneous preadipocytes were analyzed by flow cytometry (Becton Dickinson, Franklin Lakes, NJ, USA).

\subsection{EdU staining}

GCs were seeded in 96-well plates at a concentration of $2 \times 10^{3}$ per well. The granulosa cells were then treated with miR-214-3p agomir and antagomir for $48 \mathrm{~h}$ and incubated with $50 \mu \mathrm{M}$ EDU (RiboBio, Guangzhou, China) for $2 \mathrm{~h}$. The cells were washed twice with PBS, fixed with $4 \%$ paraformaldehyde for $30 \mathrm{~min}$, neutralized with $2 \mathrm{mg} / \mathrm{mL}$ glycine for $5 \mathrm{~min}$, then permeabilized with $0.5 \%$ Trixon- 100 for $5 \mathrm{~min}$. At the end of each step, the cells were washed twice with PBS for 5 min. According to the kit, the cells were incubated in a mixture of Reagents $B, C, D$, and $E$ for $30 \mathrm{~min}$. The cells were then washed three times with $0.5 \%$ Trixon- 100 , then twice with methanol. The nuclei were stained with Hoechst for $30 \mathrm{~min}$. The stained cells were finally observed on a Nikon TE2000 microscope (Nikon, Tokyo, Japan) and the data were analyzed in Image $\mathrm{J}$.

\subsection{Cell counting kit-8}

Porcine GCs were seeded in 96 well plates with 2,000 cells per well. After $48 \mathrm{~h}$ of rHhip treatment, $10 \mathrm{~mL}$ CCK8 reagent (Vazyme) was added into each well away from light, then the cells were incubated at $37{ }^{\circ} \mathrm{C}$ for 2-4 h. Finally, the plate absorbance was measured at $450 \mathrm{~nm}$.

\subsection{Luciferase reporter assay}

Luciferase reporter plasmids (psi-CHECK2) containing the wild-type 3'UTRs of Mfn2/NR5A1(WTMfn2/NR5A1) and mutant 3'UTRs of MfnFN2/NR5A1 (Mut-Mfn2/NR5A1) were obtained as manufactured by General Biosystems Co., Ltd. (Anhui, China). HEK293T was seeded in a 48-well plate. Xtreme GENE HP DNA Transfection Reagent was used to co-transfect the HEK293T cells with the wild-type or mutant 3'UTR luciferase reporter plasmids (60) and the miR-214-3p agomir or the negative control, respectively. The cells were harvested $24 \mathrm{~h}$ after transfection. Luciferase activities were measured on a Dual-Glo Luciferase AssaySystem (Promega; Madison, WI, USA) following the manufacturer's instructions. Firefly luciferase was used as a normalization control.

\subsection{ElisA}

$E_{2}$ existing in the follicular fluid and medium supernatant was detected using a porcine $E_{2}$ ElisA Kit (Nanjing Jiancheng Bioengineering Institute, Nanjing, China) operated according to the manufacturer's instructions (tolerance within batch: $\mathrm{CV}<10 \%$; tolerance between batches: $\mathrm{CV}<12 \%$; sensitivity: $20 \mathrm{e} 6000$ $\mathrm{ng} / \mathrm{L})$. 


\subsection{Bioinformatics method}

We performed a bioinformatics analysis using TargetScan, miRBase and miRTarBase. Many thousands of potential target genes were predicted. The common target gene associated with myogenes was predicted by at least these three programs. We also used KOBAS 3.0 to complete a gene ontology (GO) analysis and the Kyoto encyclopedia of genes and genomes (KEGG) for further analysis.

\subsection{Statistical analysis}

Statistical analyses were performed in GraphPad Prism 6 software. One-way analysis of variance (ANOVA) and a Newman-Keuls test were used to compare the groups. A paired Student's test was used for comparison between any two groups. Data are expressed here as the mean \pm SE and statistical significance is * $=\mathrm{P}<0.05 ; * *=\mathrm{P}<0.01$.

\section{Results}

\subsection{Biological characteristics of miR-214-3p}

We detected the expression level of miR-214-3p in the ovarian tissue of Yorkshire $\times$ Landrace sows with high-litter and low-litter characteristics in this study. We observed a higher expression in high-litter sows than in low-litter sows (Fig. 1A). The mature sequence of miR-214-3p is highly conserved across multiple species (e.g., mouse, pig, human, rat) (Fig. 1B). We also performed GO analysis on the target of miR-214$3 p$ to find that it may indeed be involved in follicular growth processes such as cell proliferation and steroid synthesis (Fig. 1C). The TGF-beta and mTOR signaling pathways play important roles in the process of follicular growth. Our KEGG pathway analysis showed that miR-214-3p participates in these signaling pathways (Fig. 1D).

\section{2 miR-214-3p overexpression promotes granulosa cells proliferation}

In order to determine the effect of miR-214-3p on the proliferation of porcine ovarian GCs, we transfected the GCs samples with miR-214-3p agomir, antagomir, and the negative control. The expression of miR214-3p increased significantly after transfection into agomir (Fig. 2A). Flow cytometry analysis indicated that miR-214-3p increased the percentage of S-phage cells (Fig. 2B,C). The EdU staining assay showed that cells were labeled positive in the miR-214-3p agomir group, unlike the negative control group (Fig. 2D,E). The CCK-8 assay also upregulated cell viability (Fig. 2F). In addition, cell cycle-related genes (Cyclin B, Cyclin E, and CDK4) showed remarkably higher mRNA and protein levels but there was no such effect in Cyclin D (Fig. 2G-I). 
To further explore the effect of miR-214-3p on GCs proliferation, we next treated the cells with antagomir$\mathrm{NC}$ and antagomir. The expression of miR-214-3p in the treatment group was dramatically reduced below the negative control group (Fig. 3A). The flow cytometry results indicated down-regulation of the S-phage cells after suppressing the expression of miR-214-3p (Fig. 3B,C). Our EdU staining assay showed that inhibition of miR-214-3p can markedly increase the number of EdU labeled positive cells (Fig. 3D,E). Our CCK-8 assay also verified the knock-down of miR-214-3p induced cell viability (Fig. 3F). RT-qPCR and Western blot data showed that miR-214-3p inhibition depressed the expression of cell cycle genes (Fig. 3G-I). In summary, miR-214-3p was found to promote GCs proliferation.

\subsection{MiR-214-3p targets Mfn2 in granulosa cells}

The experiments described above showed that miR-214-3p can promote porcine GCs proliferation (Figs. 2 and 3). To better understand the regulatory mechanism of this process, we used TargetScan7.2 and miRTarBase to predict potential target genes. We detected Mfn2 as a candidate gene from thousands of target genes (Fig. 4A) and constructed wild-type Mfn2 3'UTR and mutant Mfn2 3'UTR dual luciferase reporter vectors accordingly (Fig. 4B). We found that the dual-luciferase activity of wild-type Mfn2 3'UTR and agomir co-transfected into GCs was higher than that of co-transfected wild-type Mfn2 3'UTR and NC, while mutant dual-luciferase activity with NC and agomir appears to have no effect (Fig. 4C). Our RTqPCR and Western blot data also suggest that Mfn2 mRNA and protein levels were reduced and increased, respectively, in the miR-214-3p-agomir/antagomir groups (Fig. 4D-I). Altogether, our tests demonstrated that miR-214-3p promotes GCs proliferation by directly targeting Mfn2.

\subsection{Correlation of miR-214-3p with granulosa cells estradiol synthesis}

One of the most important functions of GCs is the secretion of estradiol. We detected the $\mathrm{E}_{2}$ concentration in our culture medium accordingly. The expression of miR-214-3p increased or decreased sharply after transfection with agomir or antagomir (Figs. 5A and 6A). The ElisA results demonstrated that $E_{2}$ concentration was markedly down-regulated or up-regulated in different treatment groups (Fig. 5B and 6B). $E_{2}$ synthesis-related genes including Star, Cyp11a1, and Cyp19a1 were also suppressed in mRNA and protein levels in the agomir group (Fig. 5C-E). The results in the antagomir treatment group were consistent with this (Fig. 6C-E). We infer that miR-214-3p inhibits GCs estradiol synthesis.

\subsection{MiR-214-3p directly inhibits NR5A1 in GCs}

NR5A1 is also referred to as "steroidogenic factor 1" and is known to regulate estradiol synthesis by regulating the transcription of Cyp11a1 and Cyp19a1 genes via binding to the nuclear receptor motifs. To explore the mechanism by which miR-214-3p regulates estradiol synthesis, we forecasted the target genes of miR-214-3p with TargetScan7.2 and miRTarBase.

Coincidentally, NR5A1 is one of the candidate target genes of miR-214-3p. This caught our attention over the course of our analysis, so we tested it specifically as a target gene of miR-214-3p (Fig. 7A). Similar to 
the results reported in Sect. 3.3, we constructed a dual luciferase reporter vector for assay (Fig. 7B); the assay revealed that miR-214-3p markedly suppressed the dual-luciferase activity (Fig. 7C). NR5A1 mRNA and protein levels were also attenuated and both increased in the miR-214-3p agomir/antagomir groups (Fig. 7D-I). These observations suggest that miR-214-3p inhibits GCs estradiol synthesis by targeting NR5A1.

\section{Discussion}

In this study, we found that miR-214-3p plays an important role in GCs proliferation and estradiol synthesis. Specifically, miR-214-3p agomir promotes GCs proliferation and inhibits estradiol synthesis while miR-214-3p antagomir inhibits proliferation and promotes estradiol synthesis. Our findings may provide workable information regarding the regulation of GCs function by miR-214-3p.

GCs function has become a popular research topic in recent years as it concerns follicle growth, follicle, development, and female reproductive disorders. Ovarian GCs, as the main somatic cells in the follicle, play a significant role in the growth and development of follicles, atresia, oocyte maturation, and ovulation (30). GCs functions such as proliferation and estradiol synthesis are affected by many regulatory factors $(31-33)$. miRNA plays an important part in these processes $(34,35)$. The results of this study suggest that miR-214-3p is highly conserved among species (Fig. 1B), which is consistent with previously published observations (22).

miR-214-3p is expressed to greatest extent in porcine ovarian tissue among other body tissues (24). Previous research has shown that miR-214-3p regulates the proliferation of breast cancer cells by targeting survivin protein (36) and can promote smooth muscle cell proliferation (37), which indicates that miR-214-3p is indeed involved in cell proliferation processes. We transfected miR-214-3p agomir and antagomir into porcine ovarian GCs in this study to explore the effects of miR-214-3p on GCs proliferation. We found that miR-214-3p promotes proliferation by upregulating the mRNA and protein levels of Cyclin B, Cyclin D, Cyclin E, and CDK4 (Figs. 2G-I and 3G-I).

We also used flow cytometry to detect the percentages of cells in the $S$ phase and found that miR-214-3p agomir and antagomir promoted and inhibited them, respectively (Figs. 2B,C and 3B,C). Our EdU staining and CCK-8 assays also showed that miR-214-3p upregulated EdU labeled positive cells and cell viability (Figs. 2D-F and 3D-F). Cyclin B is a marker of immunohistochemical proliferation (37) and CDK4 is a kinase that regulates the transition from the $\mathrm{G} 1$ to $S$ phases of the cell cycle (39). We found that due to miR-214-3p agomir and antagomir, compared to our NC, Cyclin B and CDK4 had the most significant differential expression of mRNA and protein levels.

It is commonly known that miRNA binds to the 3'UTR region of the target genes to inhibit their transcription or translation (13). Here, Mfn2 was used as a target gene of miR-214-3p as it not only reduces the Ras signaling pathway protein but also is a proliferation inhibitor. It can limit the expression of Cyclin D protein to inhibit the proliferation process (40). Feng et al. reported that miR-93 regulates 
vascular smooth muscle cell proliferation by targeting Mfn2 (41). Additionally, miR-497 promotes cardiomyocyte proliferation by downregulating the expression of Mfn2 (42).

There have been relatively few previous studies on the relationship between miR-214 and Mfn2 in cell proliferation processes. miR-214 mediates proliferation via inhibition of Mfn2 in cardiac fibroblasts (43) - a process that is relevant to Huntington's disease (44). In the present study, we found that miR-214-3p can repress the mRNA and protein levels of Mfn2 (Fig. 4D-I). Via dual-luciferase reporter assay, we also found that Mfn2 is a direct target gene of miR-214-3p in GCs (Fig. 4C).

Interestingly, we found that although miR-214-3p promoted GCs proliferation, it also inhibited the synthesis of estradiol. Similarly, addition of 150,300 , or 500 microM of stearicacid inhibits cell proliferation but stimulates estradiol-17beta production in bovine GCs (45). In human GCs, proanthocyanidin B2 can increase steroidogenesis without affecting cell proliferation (46).

Our ElisA data showed that miR-214-3p agomir reduced the concentration of $E_{2}$, while miR-214-3p antagomir enhanced the concentration of $E_{2}$ (Figs. 5B and 6B). During the synthesis of $E_{2}$, StAR can transport cholesterol from the outer to the inner mitochondrial membrane, where it is converted to pregnenolone by CYP11A1 (47). Aromatase (CYP19A1) in GCs transforms testosterone into estradiol (47, 48). We found that miR-214-3p attenuated the transcription and translation levels of Star, Cyp11a1, and Cyp19a1 (Figs. 5C-E and 6C-E). There have been no such results regarding the synthesis of estradiol by miR-214-3p published previously.

In order to further study the molecular mechanism of miR-214-3p regulating $E_{2}$ synthesis in GCs, we selected NR5A1 as the target gene and performed a dual luciferase reporter assay, RT-PCR, and Western blot experiments. Our results proved that miR-214-3p attenuates the mRNA and protein levels of NR5A1 (Fig. 7D-I), which suggested that NR5A1 may be a target gene of miR-214-3p in GCs.

Our double luciferase reporter assay also showed that miR-214-3p agomir attenuated luciferase activity, which indicates that NR5A1 is the direct target gene of miR-214-3p (Fig. 7C). NR5A1 is also, as mentioned above, the orphan receptor Steroidogenic Factor-1 (SF-1). A member of the nuclear receptor superfamily, is present in fetal and adult steroidogenic tissues and participates in the regulation of ovarian function (49). NR5A1 plays an important role in $E_{2}$ synthesis. It can bind to SF-1 response elements on the promoter of target genes such as Star, Cyp11a1, and Cyp19a1 to regulate their transcription processes $(50,51)$.

It is worth noting that many previous researchers have reached conclusions consistent with ours. For example, in mouse ovaries, miR-320 and miR-764-3p regulate estradiol synthesis by targeting SF-1 (5254).

\section{Conclusions}


In summary, as shown in Fig. 8, our results show that miR-214-3p promotes GCs proliferation by targeting Mfn2 and inhibits GCs estradiol synthesis by targeting NR5A1. The results presented here may provide workable insight into regulating the GCs functions, and follicular growth, and follicular development.

\section{Abbreviations}

GCs: granulosa cells; StAR: steroidogenic acute regulatory protein; CYP11A1: cytochrome P450 family 11 subfamily A member 1; CYP19A1: aromatase; Cyclin B: Cell cycle protein B; Cyclin D: Cell cycle protein D; Cyclin E: Cell cycle protein E; CDK4: Cyclin-dependent kinase 4; mmu: Mus musculus; ssc: Sus scrofa; hsa: Homo sapiens; rno: Rattus norvegicus; mml: Macaca mulatta; mdo: Monodelphis domestica; oan: Ornithorhynchus anatinus; tgu: Taeniopygia guttata; aca: Anolis carolinensis

\section{Declarations}

\section{Ethics approval and consent to participate}

These studies were approved by Northwest Agriculture and Forestry University Animal Research Ethics Committee (Yangling, Shaanxi, China).

\section{Consent for publication}

Not applicable

\section{Availability of data and material}

The data sets used and analysed during the current study are available from the corresponding author on reasonable request.

\section{Competing interests}

The authors declare they have no competing interest.

\section{Funding}

This work was supported by grants from the National Natural Science Foundation (No.31802047), the National Science and Technology Major Project of China (No. 2016ZX08006003) and Shanxi Provincial Key Research and Development Project (CN)『No. 2018ZDXM-NY-035区

\section{Authors' contribution}

SSJ and CGY conceived and designed the experiments; SSJ, ZXG and LJJ performed the experiments; HYM and ZLT contributed reagents/materials/analysis tools; YGS managed the project; SSJ wrote the manuscript and CGY modified the manuscript. 
Acknowledgements

The authors acknowledged all the teachers and students in Laboratory of Animal Fat Deposition \& Muscle Development.

\section{Authors' information}

${ }^{1}$ Key Laboratory of Animal Genetics, Breeding and Reproduction of Shaanxi Province, Yangling 712100, China

${ }^{2}$ Laboratory of Animal Fat Deposition \& Muscle Development, College of Animal Science and Technology, Northwest A\&F University, Yangling 712100, China

\section{References}

1. Boyer A, Lapointe E, Zheng X, Cowan RG, Li H, Quirk SM, et al. WNT4 is required for normal ovarian follicle development and female fertility. FASEB J. [Journal Article; Research Support, N.I.H., Extramural; Research Support, Non-U.S. Gov't]. 2010 2010-08-01;24(8):3010-25.

2. Pangas SA, Matzuk MM. Genetic models for transforming growth factor beta superfamily signaling in ovarian follicle development. MOL CELL ENDOCRINOL. [Journal Article; Research Support, U.S. Gov't, P.H.S.; Review]. 2004 2004-10-15;225(1-2):83-91.

3. Wang W, Yin L, Bai L, Ma G, Zhao C, Xiang A, et al. Bmal1 interference impairs hormone synthesis and promotes apoptosis in porcine granulosa cells. THERIOGENOLOGY. [Journal Article]. 2017 201709-01;99:63-8.

4. Bai L, Chu G, Mai Y, Zheng J, Wang W, Zhang Q, et al. Identification and expression analyses of BAMBI mediated by FSH in swine luteinizing granulosa cells. THERIOGENOLOGY:;82(8):1094-101.

5. Mani AM, Fenwick MA, Cheng Z, Sharma MK, Singh D, Wathes DC. IGF1 induces up-regulation of steroidogenic and apoptotic regulatory genes via activation of phosphatidylinositol-dependent kinase/AKT in bovine granulosa cells. 2010;139(1):139.

6. Zhao GS, Wei HK, Yan JZ, Shan Y, NING LU JI, Zheng GU, et al. A novel ubiquitin carboxyl terminal

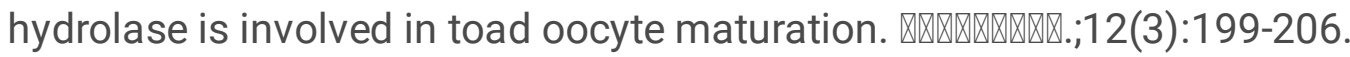

7. Chen S, Wu RF, Su L, Zhou WD, Zhu MB, Chen QH. Lipoxin A4 regulates expression of the estrogen receptor and inhibits 17 beta-estradiol induced p38 mitogen-activated protein kinase phosphorylation in human endometriotic stromal cells. FERTIL STERIL. [Journal Article; Research Support, Non-U.S. Gov't]. 2014 2014-07-01;102(1):264-71.

8. Umer S, Sammad A, Zou H, Khan A, Weldegebriall SB, Hao H, et al. Regulation of AMH, AMHR-II, and BMPs $(2,6)$ Genes of Bovine Granulosa Cells Treated with Exogenous FSH and Their Association with Protein Hormones. Genes (Basel). [Journal Article; Research Support, Non-U.S. Gov't]. 2019 2019-12-12;10(12). 
9. Hershlag A, Lesser M, Montefusco D, Lavy G, Kaplan P, Liu HC, et al. Interinstitutional variability of follicle-stimulating hormone and estradiol levels. FERTIL STERIL. [Comparative Study; Journal Article]. 1992 1992-12-01;58(6):1123-6.

10. Dewailly D, Robin G, Peigne M, Decanter C, Pigny P, Catteau-Jonard S. Interactions between androgens, $\mathrm{FSH}$, anti-Mullerian hormone and estradiol during folliculogenesis in the human normal and polycystic ovary. HUM REPROD UPDATE. [Journal Article; Review]. 2016 2016-11-01;22(6):70924.

11. Tian C, Liu L, Ye X, Fu H, Sheng X, Wang L, et al. Functional Oocytes Derived from Granulosa Cells. CELL REP. [Journal Article]. 2019 2019-12-24;29(13):4256-67.

12. Peluso JJ, Delidow BC, Lynch J, White BA. Follicle-stimulating hormone and insulin regulation of 17 beta-estradiol secretion and granulosa cell proliferation within immature rat ovaries maintained in perifusion culture. ENDOCRINOLOGY. [Journal Article; Research Support, Non-U.S. Gov't]. 1991 199101-01;128(1):191-6.

13. Shen G, Sun Q, Yao Y, Li S, Liu G, Yuan C, et al. Role of ADAM9 and miR-126 in the development of abdominal aortic aneurysm. ATHEROSCLEROSIS. [Journal Article]. 2020 2020-02-01;297:47-54.

14. Ding Q, Jin M, Wang Y, Liu J, Kalds P, Wang Y, et al. Transactivation of miR-202-5p by Steroidogenic Factor 1 (SF1) Induces Apoptosis in Goat Granulosa Cells by Targeting TGFbetaR2. CELLS-BASEL. [Journal Article]. 2020 2020-02-14;9(2).

15. Wang L, Li C, Li R, Deng Y, Tan Y, Tong C, et al. MicroRNA-764-3p regulates 17beta-estradiol synthesis of mouse ovarian granulosa cells by targeting steroidogenic factor-1. In Vitro Cell Dev Biol Anim. [Journal Article; Research Support, Non-U.S. Gov't]. 2016 2016-03-01;52(3):365-73.

16. Ding Q, Jin M, Wang Y, Liu J, Kalds P, Wang Y, et al. Transactivation of miR-202-5p by Steroidogenic Factor 1 (SF1) Induces Apoptosis in Goat Granulosa Cells by Targeting TGFbetaR2. CELLS-BASEL. [Journal Article]. 2020 2020-02-14;9(2).

17. Liu J, Li X, Yao Y, Li Q, Pan Z, Li Q. miR-1275 controls granulosa cell apoptosis and estradiol synthesis by impairing LRH-1/CYP19A1 axis. Biochim Biophys Acta Gene Regul Mech. [Journal Article; Research Support, Non-U.S. Gov't]. 2018 2018-03-01;1861(3):246-57.

18. Desvignes T, Contreras A, Postlethwait JH. Evolution of the miR199-214 cluster and vertebrate skeletal development. RNA BIOL. [Journal Article; Research Support, N.I.H., Extramural]. 2014 201401-20;11(4):281-94.

19. Lee YB, Bantounas I, Lee DY, Phylactou L, Caldwell MA, Uney JB. Twist-1 regulates the miR-199a/214 cluster during development. NUCLEIC ACIDS RES. [Journal Article; Research Support, Non-U.S. Gov't]. 2009 2009-01-01;37(1):123-8.

20. Chen Y, Du H, Bao L, Liu W. LncRNA PVT1 promotes ovarian cancer progression by silencing miR214. CANCER BIOL MED. [Journal Article]. 2018 2018-08-01;15(3):238-50.

21. Wang J, Yang LZ, Zhang JS, Gong JX, Wang YH, Zhang CL, et al. Effects of microRNAs on skeletal muscle development. GENE. [Journal Article; Review]. 2018 2018-08-20;668:107-13. 
22. Xi FX, Wei CS, Xu YT, Ma L, He YL, Shi XE, et al. MicroRNA-214-3p Targeting Ctnnb1 Promotes 3T3-L1 Preadipocyte Differentiation by Interfering with the Wnt/beta-Catenin Signaling Pathway. INT J MOL SCI. [Journal Article]. 2019 2019-04-12;20(8).

23. Huang L, Yin ZJ, Feng YF, Zhang XD, Wu T, Ding YY, et al. Identification and differential expression of microRNAs in the ovaries of pigs (Sus scrofa) with high and low litter sizes. ANIM GENET. [Journal Article]. 2016 2016-10-01;47(5):543-51.

24. Tian $M$, Zhang $X$, Ye $P$, Tao Q, Zhang L, Ding Y, et al. MicroRNA-21 and microRNA-214 play important role in reproduction regulation during porcine estrous. ANIM SCI J. [Journal Article]. 2018 2018-1001;89(10):1398-405.

25. Yin L, Wang W, Wei H, Xi F, Chu G, Yang G. Localization and expression of CTRP6 in ovary and its regulation by FSH in porcine granulosa cells. THERIOGENOLOGY. [Journal Article]. 2019 2019-0315;127:56-65.

26. Chu G, Zhou X, Hu Y, Shi S, Yang G. Rev-erbalpha Inhibits Proliferation and Promotes Apoptosis of Preadipocytes through the Agonist GSK4112. INT J MOL SCI. [Journal Article]. 2019 2019-0912;20(18).

27. Wang J, Ge J, Cao H, Zhang X, Guo Y, Li X, et al. Leptin Promotes White Adipocyte Browning by Inhibiting the Hh Signaling Pathway. CELLS-BASEL. [Journal Article; Research Support, Non-U.S. Gov't]. 2019 2019-04-24;8(4).

28. Wei H, Li J, Shi S, Zhang L, Xiang A, Shi X, et al. Hhip inhibits proliferation and promotes differentiation of adipocytes through suppressing hedgehog signaling pathway. Biochem Biophys Res Commun. [Journal Article]. 2019 2019-06-18;514(1):148-56.

29. Huang K, Shi X, Wang J, Yao Y, Peng Y, Chen X, et al. Upregulated microRNA-106a Promotes Porcine Preadipocyte Proliferation and Differentiation by Targeting Different Genes. Genes (Basel). [Journal Article; Research Support, Non-U.S. Gov't]. 2019 2019-10-14;10(10).

30. Wang W, Yin L, Bai L, Ma G, Zhao C, Xiang A, et al. Bmal1 interference impairs hormone synthesis and promotes apoptosis in porcine granulosa cells. THERIOGENOLOGY. [Journal Article]. 2017 201709-01;99:63-8.

31. Wang J, Qiu J, Bo L, Wu Z, Zhou A, Xu W, et al. WT1 influences apoptosis and proliferation of immature mice granular cells through regulation of the wnt/beta-catenin signal pathway. Cell Mol Biol (Noisy-le-grand). [Journal Article]. 2019 2019-09-30;65(7):138-45.

32. Qin Y, Tang T, Li W, Liu Z, Yang X, Shi X, et al. Bone Morphogenetic Protein 15 Knockdown Inhibits Porcine Ovarian Follicular Development and Ovulation. Front Cell Dev Biol. [Journal Article]. 2019 2019-01-20;7:286.

33. Liu Y, Yang Y, Li W, Ao H, Zhang Y, Zhou R, et al. Effects of melatonin on the synthesis of estradiol and gene expression in pig granulosa cells. J PINEAL RES. [Journal Article]. 2019 2019-0301;66(2):e12546.

34. Pande HO, Tesfaye D, Hoelker M, Gebremedhn S, Held E, Neuhoff C, et al. MicroRNA-424/503 cluster members regulate bovine granulosa cell proliferation and cell cycle progression by targeting SMAD7 
gene through activin signalling pathway. J OVARIAN RES. [Journal Article]. 2018 2018-0501;11(1):34.

35. Li Q, Du X, Pan Z, Zhang L, Li Q. The transcription factor SMAD4 and miR-10b contribute to E2 release and cell apoptosis in ovarian granulosa cells by targeting CYP19A1. MOL CELL ENDOCRINOL. [Journal Article; Research Support, Non-U.S. Gov't]. 2018 2018-11-15;476:84-95.

36. Han LC, Wang H, Niu FL, Yan JY, Cai HF. Effect miR-214-3p on proliferation and apoptosis of breast cancer cells by targeting survivin protein. Eur Rev Med Pharmacol Sci. [Journal Article]. 2019 201909-01;23(17):7469-74.

37. Xing XQ, Li B, Xu SL, Liu J, Zhang CF, Yang J. MicroRNA-214-3p Regulates Hypoxia-Mediated Pulmonary Artery Smooth Muscle Cell Proliferation and Migration by Targeting ARHGEF12. Med Sci Monit. [Journal Article]. 2019 2019-08-02;25:5738-46.

38. Koliadi A, Nilsson C, Holmqvist M, Holmberg L, de La Torre M, Warnberg F, et al. Cyclin B is an immunohistochemical proliferation marker which can predict for breast cancer death in low-risk node negative breast cancer. ACTA ONCOL. [Comparative Study; Journal Article; Research Support, NonU.S. Gov't]. 2010 2010-08-01;49(6):816-20.

39. Grison A, Gaiser C, Bieder A, Baranek C, Atanasoski S. Ablation of cdk4 and cdk6 affects proliferation of basal progenitor cells in the developing dorsal and ventral forebrain. DEV NEUROBIOL. [Journal Article]. 2018 2018-07-01;78(7):660-70.

40. Liu X, Sun J, Yuan P, Shou K, Zhou Y, Gao W, et al. Mfn2 inhibits proliferation and cell-cycle in Hela cells via Ras-NF-kappaB signal pathway. CANCER CELL INT. [Journal Article]. 2019 2019-0120;19:197.

41. Feng $S$, Gao L, Zhang D, Tian X, Kong L, Shi H, et al. MiR-93 regulates vascular smooth muscle cell proliferation, and neointimal formation through targeting Mfn2. INT J BIOL SCl. [Journal Article]. 2019 2019-01-20;15(12):2615-26.

42. Qin L, Yang W, Wang YX, Wang ZJ, Li CC, Li M, et al. MicroRNA-497 promotes proliferation and inhibits apoptosis of cardiomyocytes through the downregulation of Mfn2 in a mouse model of myocardial ischemia-reperfusion injury. BIOMED PHARMACOTHER. [Journal Article]. 2018 2018-0901;105:103-14.

43. Sun M, Yu H, Zhang Y, Li Z, Gao W. MicroRNA-214 Mediates Isoproterenol-induced Proliferation and Collagen Synthesis in Cardiac Fibroblasts. Sci Rep. [Journal Article; Research Support, Non-U.S. Gov't]. 2015 2015-12-22;5:18351.

44. Bucha S, Mukhopadhyay D, Bhattacharyya NP. Regulation of mitochondrial morphology and cell cycle by microRNA-214 targeting Mitofusin2. Biochem Biophys Res Commun. [Journal Article; Research Support, Non-U.S. Gov't]. 2015 2015-10-02;465(4):797-802.

45. Vanholder T, Leroy JL, Soom AV, Opsomer G, Maes D, Coryn M, et al. Effect of non-esterified fatty acids on bovine granulosa cell steroidogenesis and proliferation in vitro. ANIM REPROD SCI. [Journal Article; Research Support, Non-U.S. Gov't]. 2005 2005-06-01;87(1-2):33-44. 
46. Barbe A, Rame C, Mellouk N, Estienne A, Bongrani A, Brossaud A, et al. Effects of Grape Seed Extract and Proanthocyanidin B2 on In Vitro Proliferation, Viability, Steroidogenesis, Oxidative Stress, and Cell Signaling in Human Granulosa Cells. INT J MOL SCI. [Journal Article]. 2019 2019-08-28;20(17).

47. Hebert-Schuster M, Rotta BE, Kirkpatrick B, Guibourdenche J, Cohen M. The Interplay between Glucose-Regulated Protein 78 (GRP78) and Steroids in the Reproductive System. INT J MOL SCI. [Journal Article; Review]. 2018 2018-06-22;19(7).

48. Bai L, Chu G, Wang W, Xiang A, Yang G. BAMBI promotes porcine granulosa cell steroidogenesis involving TGF-beta signaling. THERIOGENOLOGY. [Journal Article]. 2017 2017-09-15;100:24-31.

49. Mlynarczuk J, Wrobel MH, Rekawiecki R, Kotwica J. The expression of Steroidogenic Factor-1 and its role in bovine steroidogenic ovarian cells during the estrus cycle and first trimester of pregnancy. ANIM REPROD SCI. [Journal Article; Research Support, Non-U.S. Gov't]. 2013 2013-04-01;138(1-2):7481.

50. Lai WA, Yeh YT, Fang WL, Wu LS, Harada N, Wang PH, et al. Calcineurin and CRTC2 mediate FSH and TGFbeta1 upregulation of Cyp19a1 and Nr5a in ovary granulosa cells. J MOL ENDOCRINOL. [Journal Article; Research Support, Non-U.S. Gov't]. 2014 2014-10-01;53(2):259-70.

51. Wang J, Gong Y. Transcription of CYP19A1 is directly regulated by SF-1 in the theca cells of ovary follicles in chicken. Gen Comp Endocrinol. [Journal Article]. 2017 2017-06-01;247:1-7.

52. Yin M, Lu M, Yao G, Tian H, Lian J, Liu L, et al. Transactivation of microRNA-383 by steroidogenic factor-1 promotes estradiol release from mouse ovarian granulosa cells by targeting RBMS1. MOL ENDOCRINOL. [Journal Article; Research Support, Non-U.S. Gov't]. 2012 2012-07-01;26(7):1129-43.

53. Yin $M$, Wang $X$, Yao G, Lu M, Liang M, Sun $Y$, et al. Transactivation of micrornA-320 by microRNA-383 regulates granulosa cell functions by targeting E2F1 and SF-1 proteins. J BIOL CHEM. [Journal Article; Research Support, Non-U.S. Gov't]. 2014 2014-06-27;289(26):18239-57.

54. Wang L, Li C, Li R, Deng Y, Tan Y, Tong C, et al. MicroRNA-764-3p regulates 17beta-estradiol synthesis of mouse ovarian granulosa cells by targeting steroidogenic factor-1. In Vitro Cell Dev Biol Anim. [Journal Article; Research Support, Non-U.S. Gov't]. 2016 2016-03-01;52(3):365-73.

\section{Table}

Due to technical limitations, Table 1 is provided in the Supplementary Files section.

\section{Figures}


A

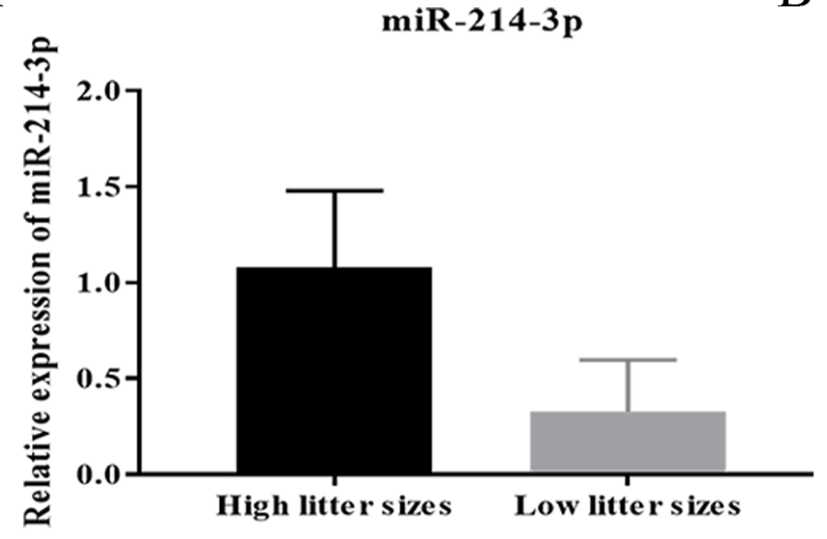

C

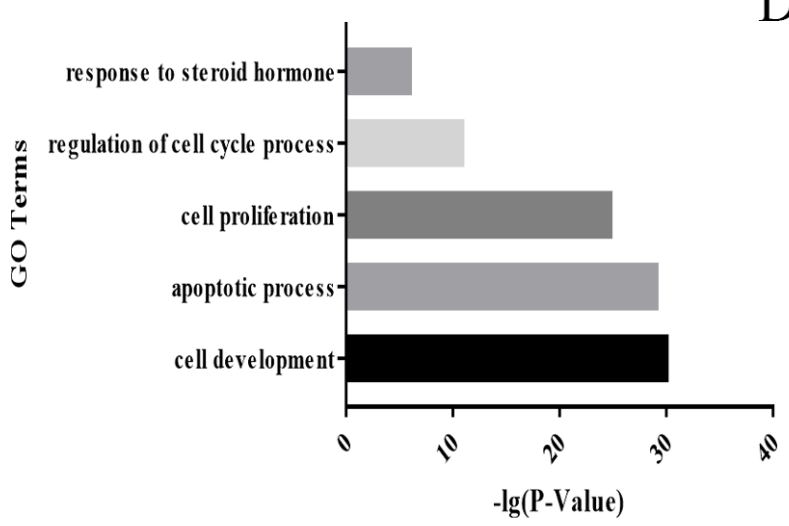

B

$\mathrm{D}$
>mmu-miR-214-3p ACAGCAGGCACAGACAGGCAGU >ssc-miR-214-3p ACAGCAGGCACAGACAGGCAG

$>$ hsa-miR-214-3p ACAGCAGGCACAGACAGGCAGU

>mo-miR-214-3p ACAGCAGGCACAGACAGGCAG

$>$ mml-miR-214-3p ACAGCAGGCACAGACAGGCAG

$>$ mdo-miR-214-3p ACAGCAGGCACAGACAGGCAG

$>0 a n$-miR-214-3p ACAGCAGGCACAGACAGGCAGU

$>$ tgu-miR-214-3p ACAGCAGGCACAGACAGGCAGU

>aca-miR-214-3p ACAGCAGGCACAGACAGGCAGU

Seed sequence

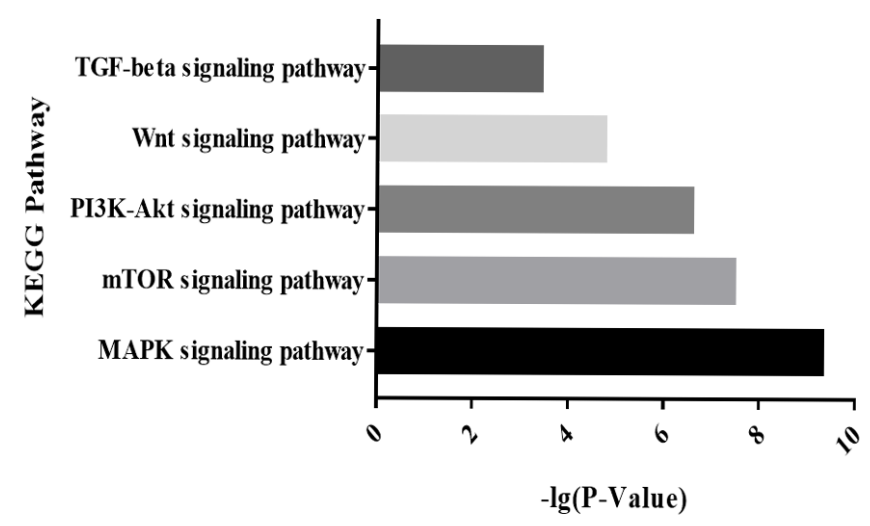

\section{Figure 1}

Expression level of miR-214-3p in porcine ovarian tissue (high-litter, low-litter) and bioinformatics analysis. (A) RT-qPCR analysis of miR-214-3p expression; (B) Sequence of mature miR-214-3p highly conserved across species; (C) GO term analysis of miR-214-3p; (D) KEGG pathway analysis of miR-214$3 p$. 
A

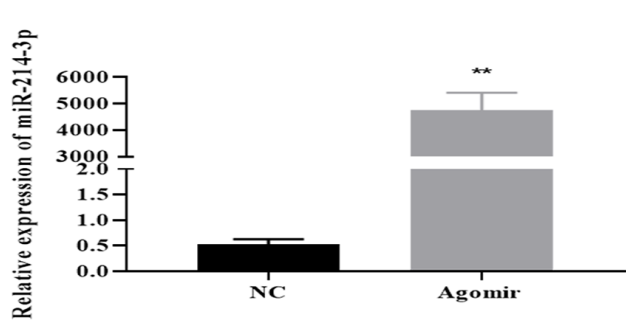

B
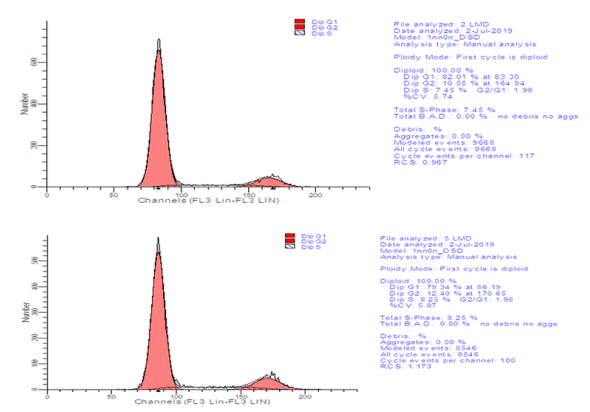

C
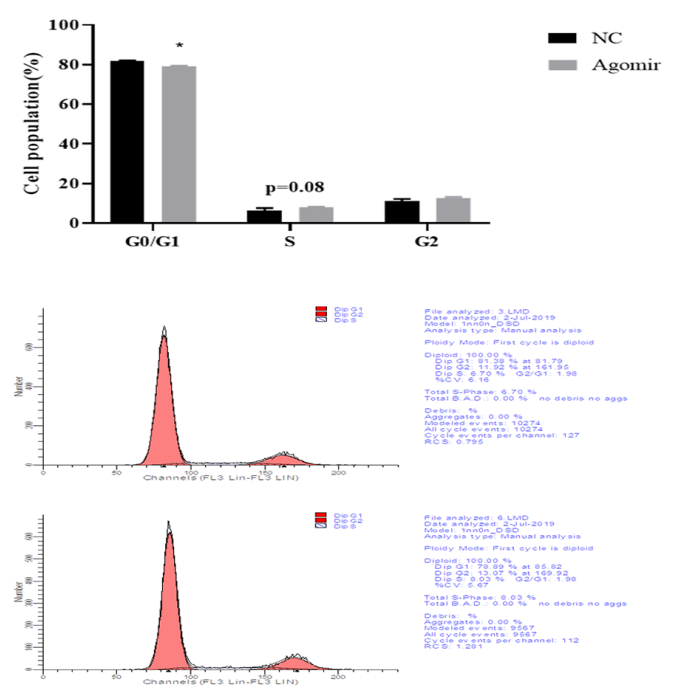

D

EdU

Hochst

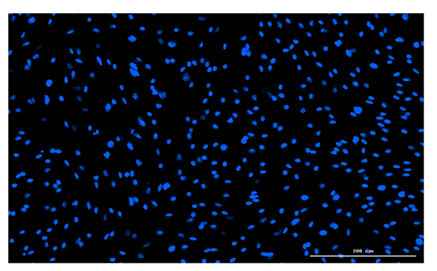

Merge
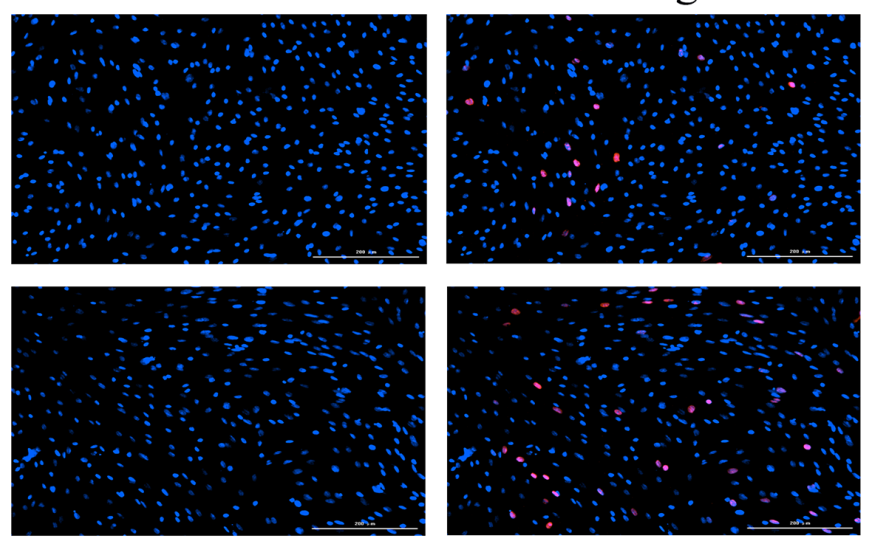

E

F

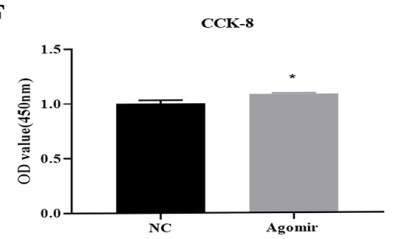

G

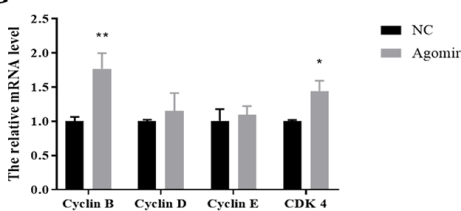

I

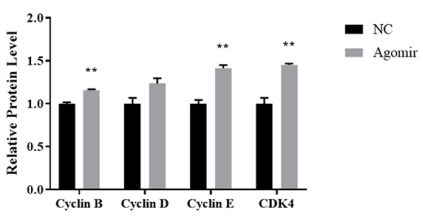

\section{Figure 2}

Overexpression of miR-214-3p promotes porcine GCs proliferation. miR-214-3p agomir or negative control (NC) were transfected into cells which were then harvested after $24 \mathrm{~h}$. (A) Overexpression efficiency of miR-214-3p after transfection with miR-214-3p agomir compared to NC; (B) Flow cytometry determines cell percentages in different cycle phases; (C) Cell cycle analysis statistical results; (D) EdU staining assay of proliferous cell quantities - positive cells stained by EdU (red) and total cell nucleus stained 
with Hoechst (blue); (E) Results presented as red/blue cell nuclei; (F) CCK-8 assay detects cell viability after 24-h transfection as absorbance value at $450 \mathrm{~nm}$ after incubation with 10\% CCK-8 solution for $4 \mathrm{~h}$; (G) RT-qPCR detects cell cycle genes, Cyclin B, Cyclin E, Cyclin D, CDK4 after 24-h transfection; (H) Western blot analysis of cell cycle genes; (I) Quantification of Western blot analysis of Cyclin B, Cyclin D, Cyclin E, CDK4. Note: Data are mean \pm SEM of three independent experiments; ${ }^{*} p<0.05,{ }^{* \star} p<0.01$.
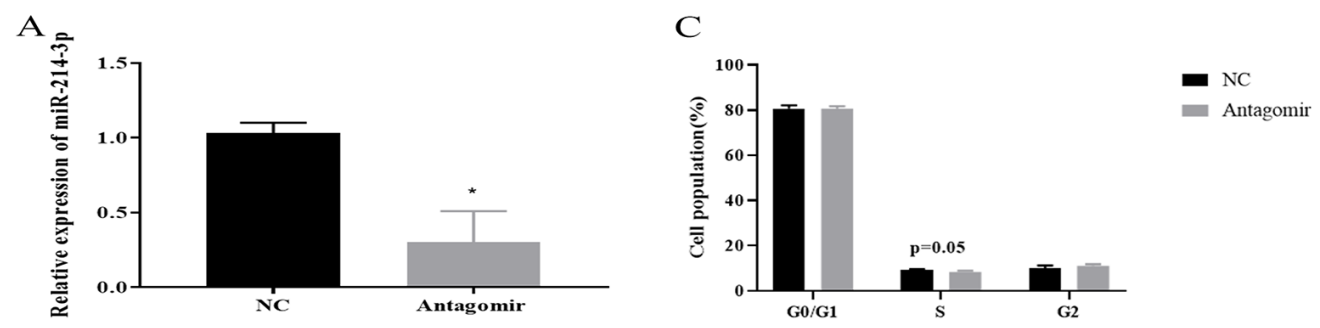

B
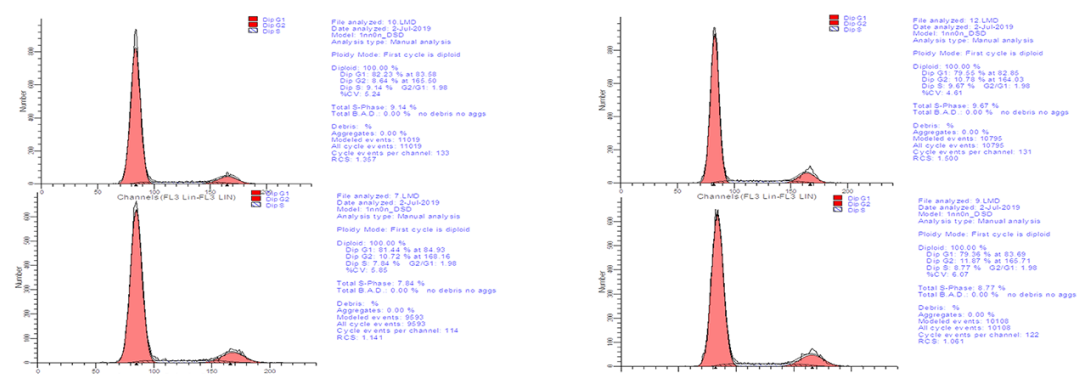

$\mathrm{D}$

EdU

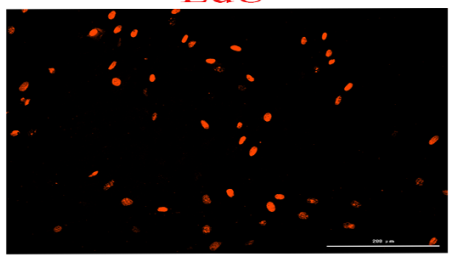

Hochst

Merge
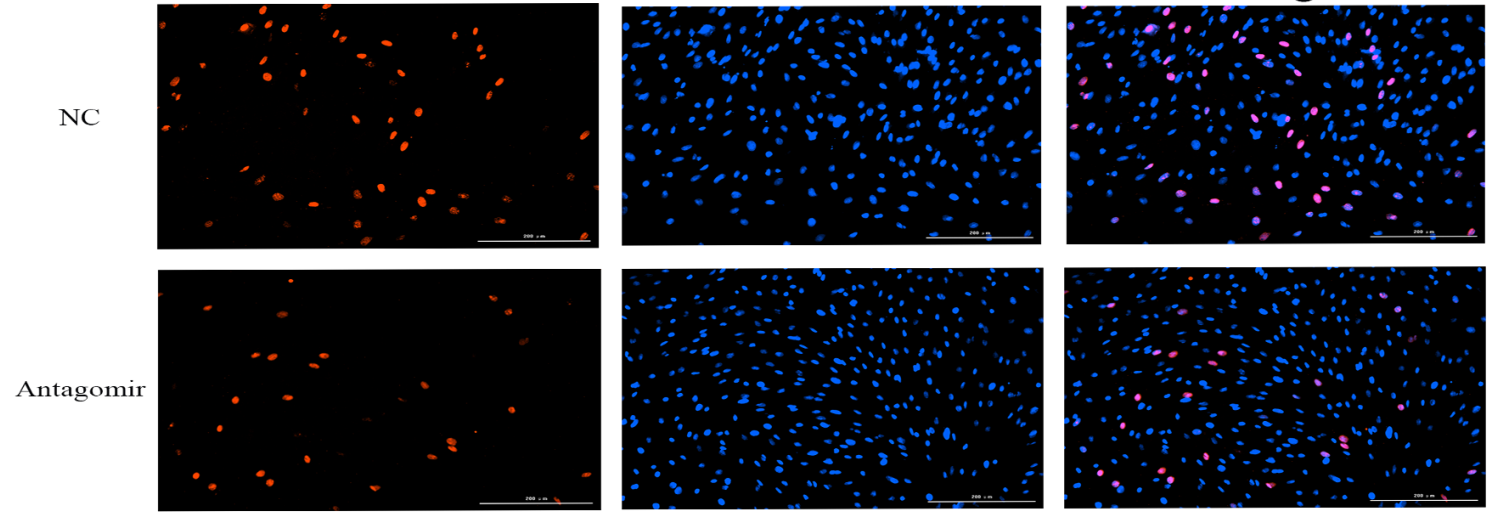

$\mathrm{E}$

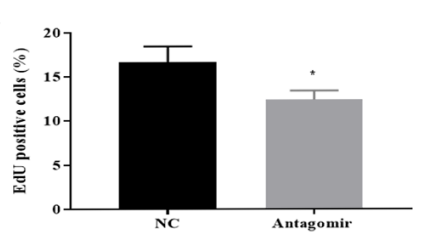

H Cyclin B Cyclin B

Cyclin B CDK 4 GAPDH F

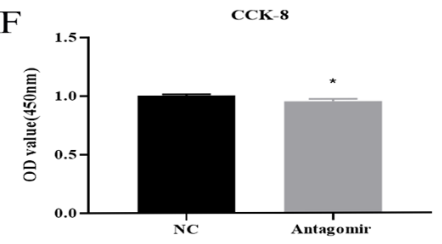

I

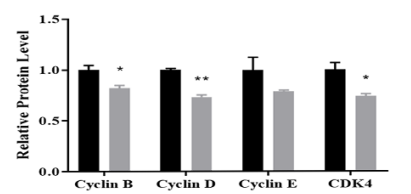

NC Antagomir NC Antagomir
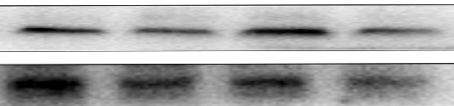

$-$

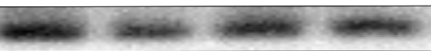

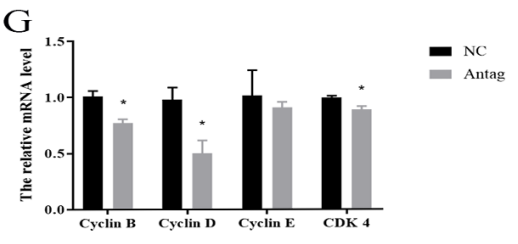

- ${ }_{\text {Antagomi }}^{\text {Ant }}$

Figure 3 
miR-214-3p inhibitor inhibits porcine GCs proliferation. miR-214-3p antagomir or NC were transfected into cells which were then harvested after $24 \mathrm{~h}$. (A) Knock-down efficiency of miR-214-3p after transfection with miR-214-3p antagomir compared to NC; (B) Flow cytometry determines cell percentages in different cycle phases; (C) Cell cycle analysis statistical results; (D) EdU staining assays proliferous cell quantities- positive cells stained by EdU (red) and total cell nucleus stained with Hoechst (blue); (E) Results represented as red/blue cell nuclei percentages; (F) CCK-8 assay detects cell viability after 24-h transfection as absorbance value at $450 \mathrm{~nm}$ after incubation with $10 \%$ CCK-8 solution for $4 \mathrm{~h}$; (G) RTqPCR detects cell cycle genes, Cyclin B, Cyclin E, Cyclin D, CDK4 after 24-h transfection; (H) Western blot analysis of cell cycle genes; (I) Quantification of Western blot analysis of Cyclin B, Cyclin D, Cyclin E, CDK4. Note: Data represent mean \pm SEM of three independent experiments; ${ }^{*} p<0.05,{ }^{* *} p<0.01$. 
A

B
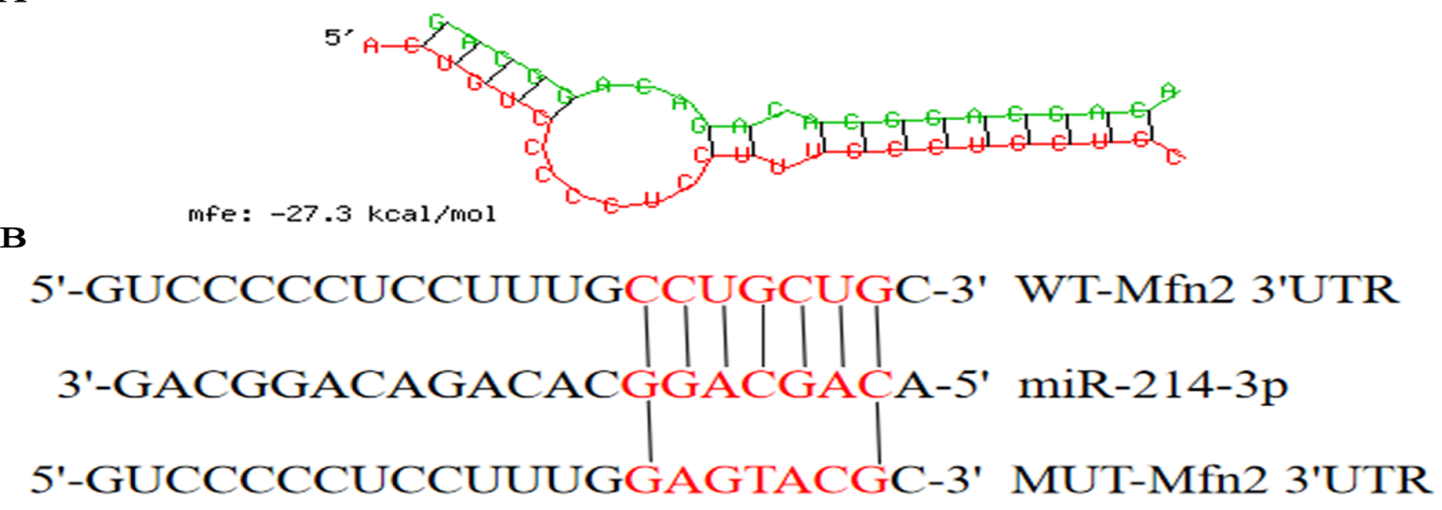

C

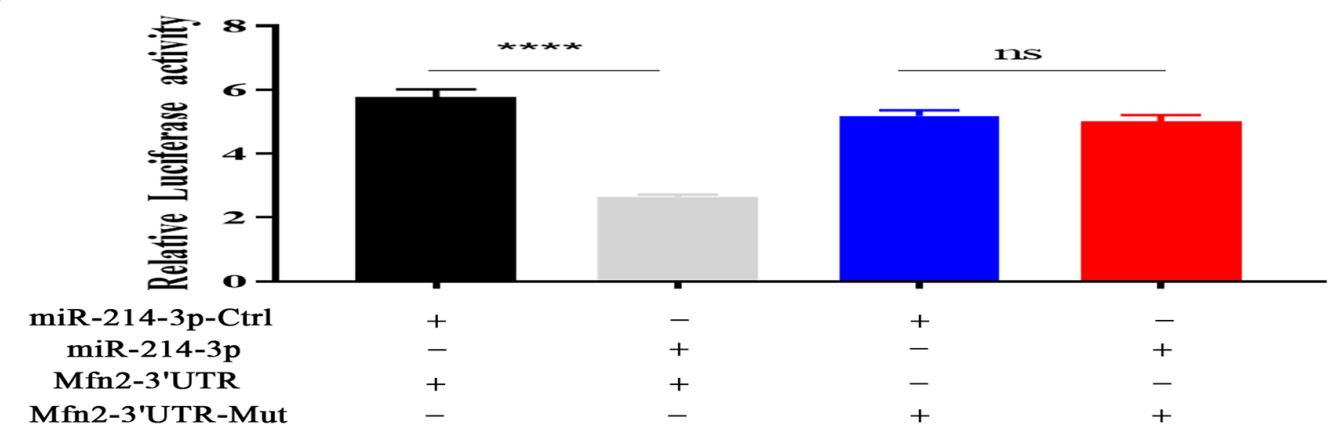

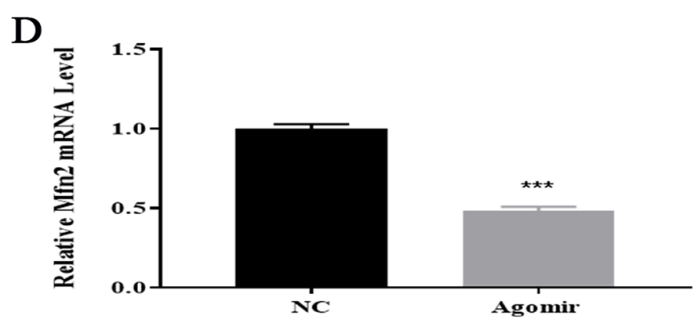

F
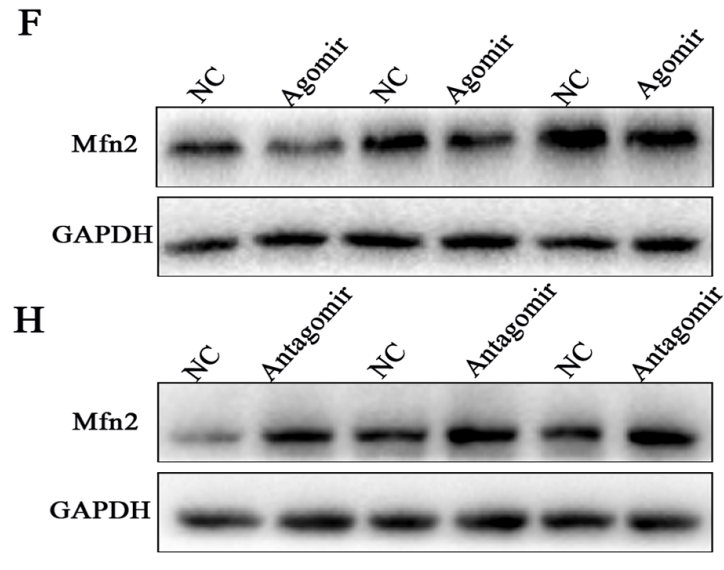

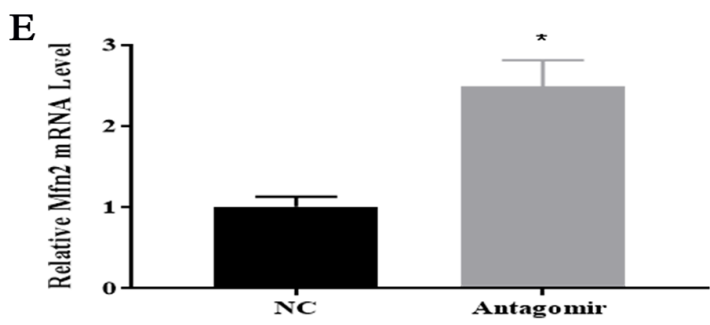

G

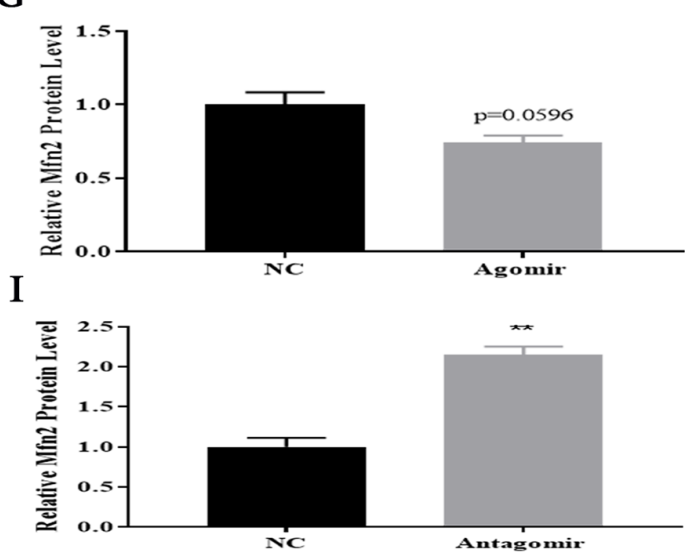

\section{Figure 4}

MiR-214-3p targets Mfn2 during GCs proliferation. (A) miR-214-3p binding site within te Mfn2 3'-UTR predicted by RNAhybrid; (B) Target site of miR-214-3p within porcine Mfn2 mRNA 3'UTR and mutational site of Mfn2 3'UTR; (C) Dual luciferase assay by co-transfection of miR-214-3p agomir and wild-type vectors or mutant vectors - relative luciferase activity represented by Renilla Luciferase/Firefly Luciferase (RLUC/FLUC); (D) Relative Mfn2 mRNA expression levels after treatment with miR-214-3p agomir; (E) 
Relative Mfn2 mRNA expression levels after treatment with miR-214-3p antagomir; (F) Western blot analysis of Mfn2 protein expression after treatment with miR-214-3p agomir; $(\mathrm{H})$ Western blot analysis of Mfn2 protein expression after treatment with miR-214-3p antagomir; (G,I) Mfn2 protein level quantifications. Note: Data are mean \pm SEM of three independent experiments. ${ }^{*} p<0.05,{ }^{*} p<0.01$.

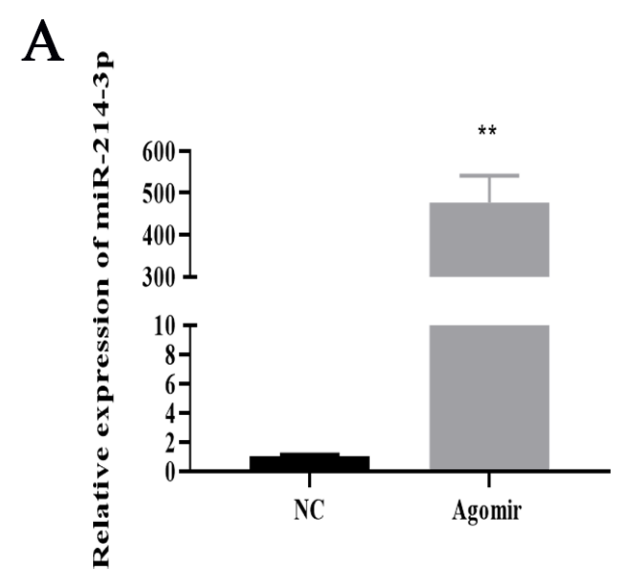

B
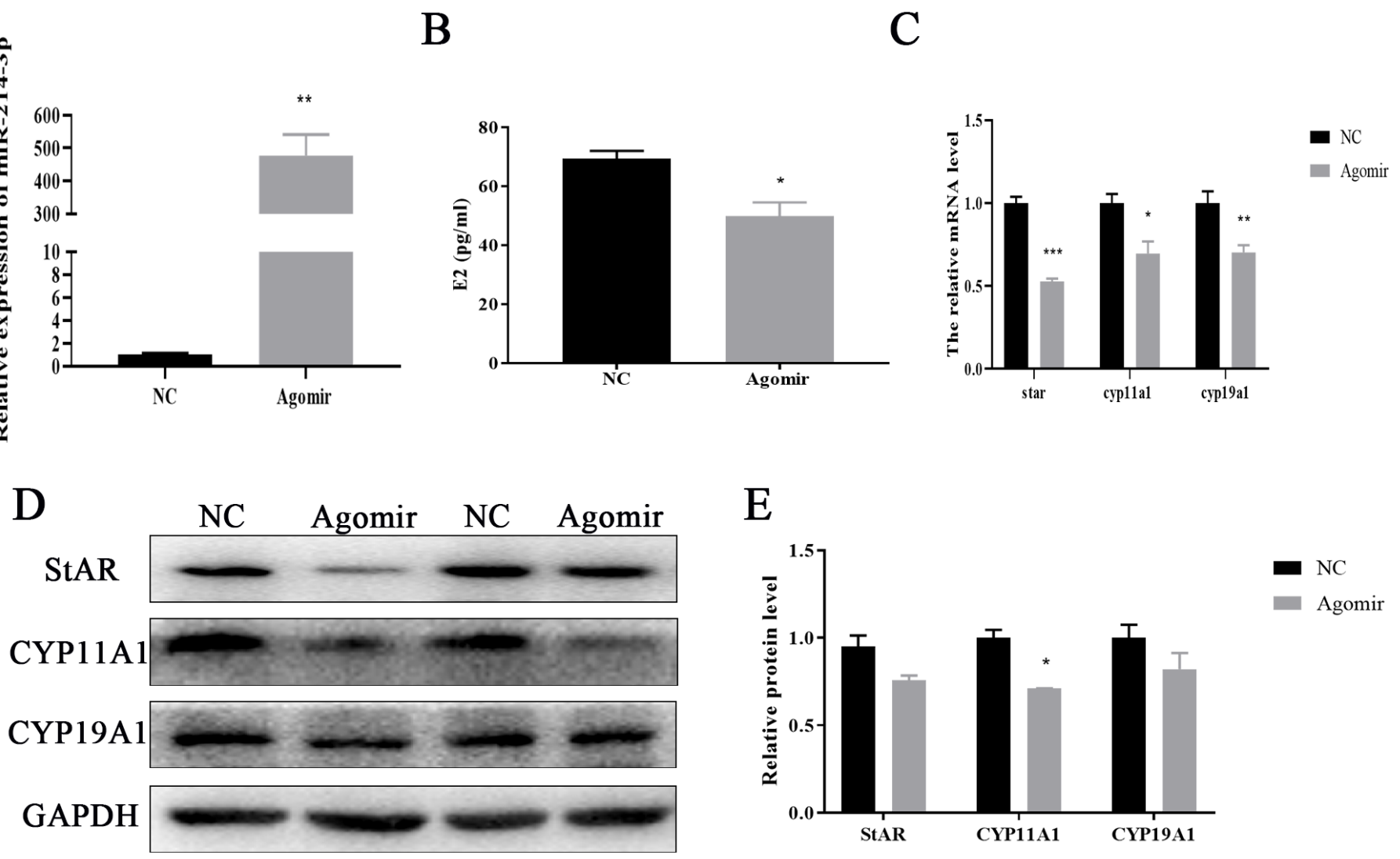

\section{Figure 5}

Overexpression of miR-214-3p inhibits porcine GCs estradiol synthesis. miR-214-3p agomir or NC were transfected into cells which were harvested after $24 \mathrm{~h}$. (A) Overexpression efficiency of miR-214-3p after transfection with miR-214-3p agomir compared to NC; (B) Estradiol concentration detected by ElisA culture supernatants collected $24 \mathrm{~h}$ after miR-214-3p agomir and NC treatment; (C) RT-qPCR detects E2 synthesis-related genes including Star, Cyp11a1, and Cyp19a1 after 24-h transfection; (D) Western blot analysis of E2 synthesis-related genes; (E) Quantification of Western blot analysis of StAR, CYP11A1, CYP19A1. Note: Data are mean \pm SEM of three independent experiments; ${ }^{\star} p<0.05,{ }^{\star \star} p<0.01$. 


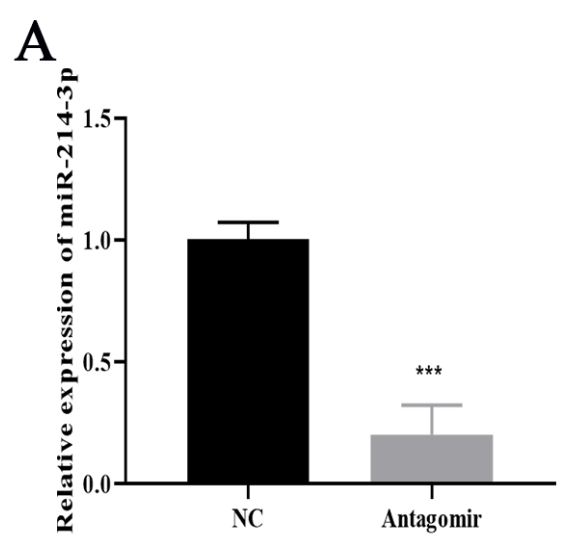

D

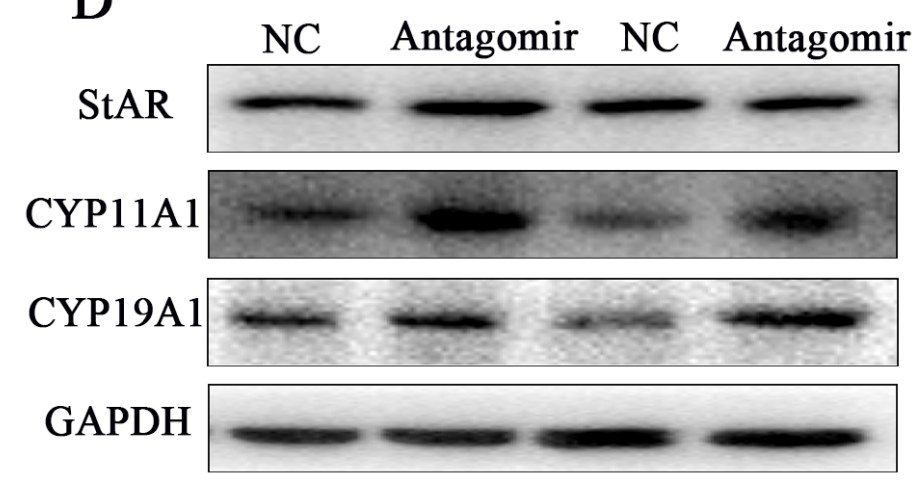

B

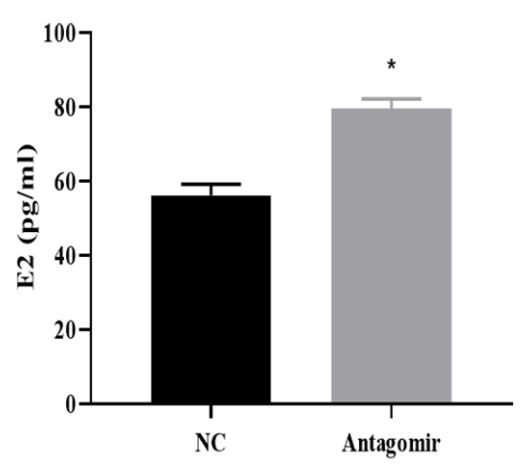

C

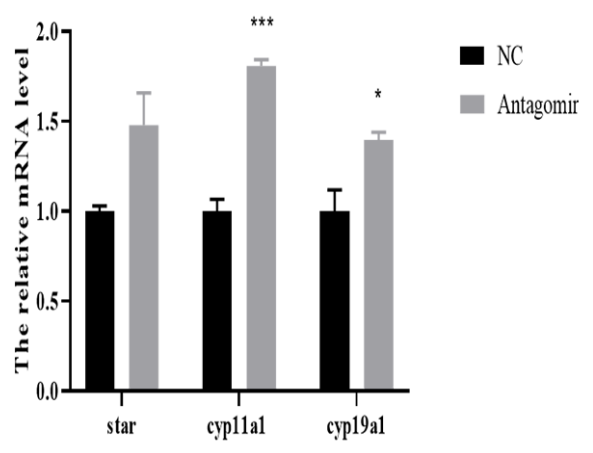

E 
A

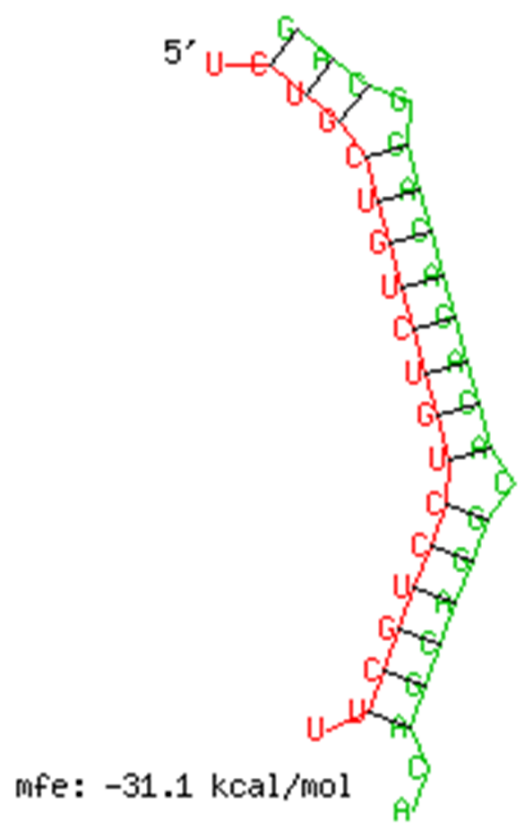

B

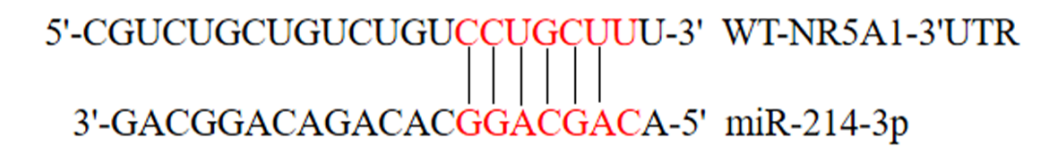

5'-CGUCUGCUGUCUGUAACCUGCU-3' MUT-NR5A1-3'UTR

$\mathrm{C}$

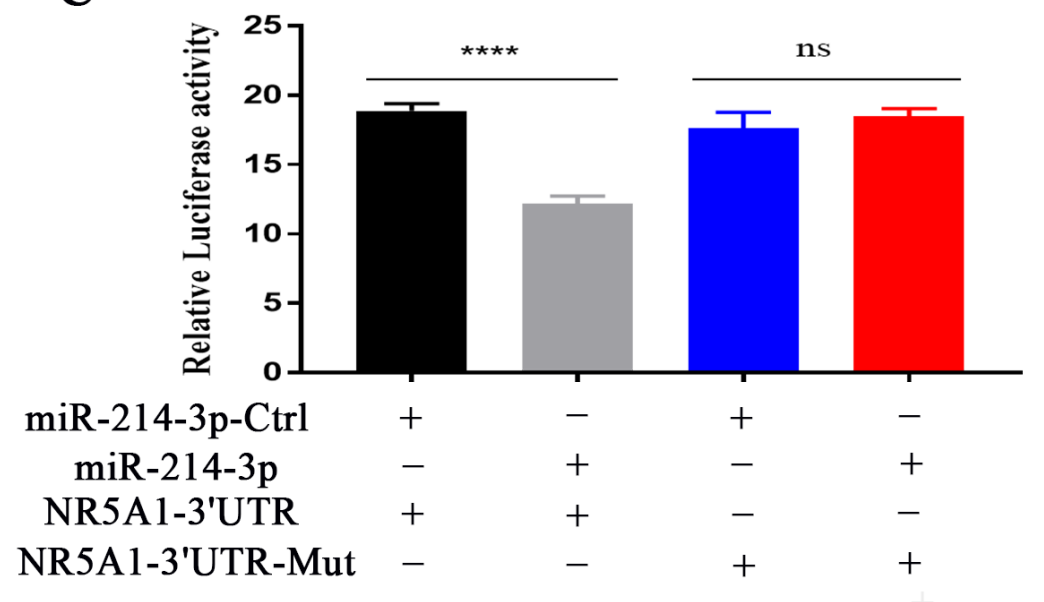

$\mathrm{E}$

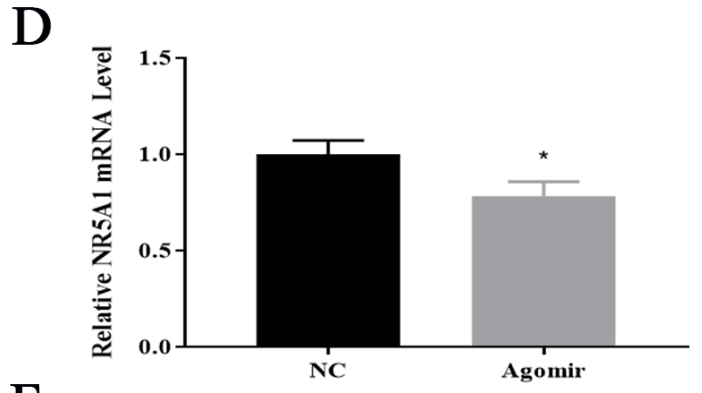

$\mathrm{F}$

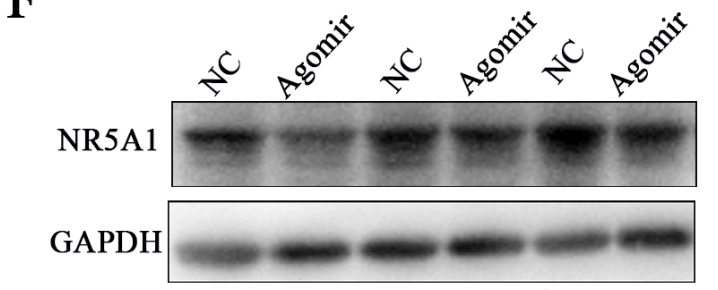

$\mathrm{H}$

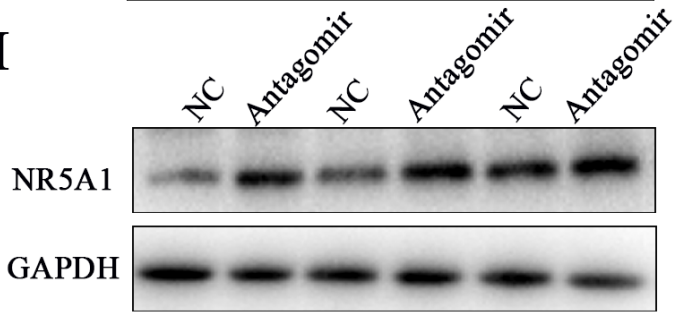

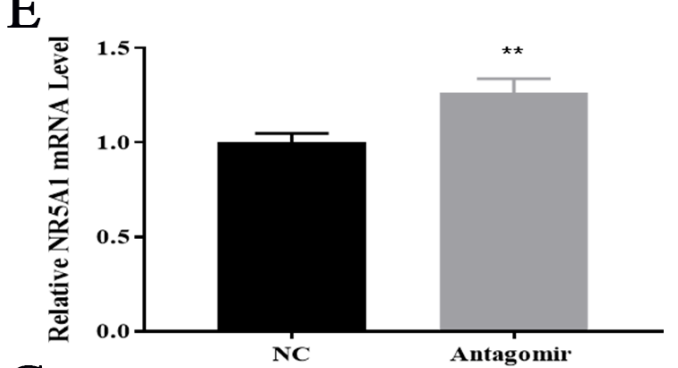

G

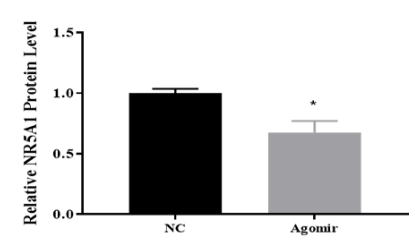

I

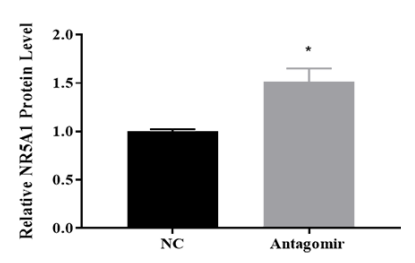

\section{Figure 7}

MiR-214-3p targets NR5A1 during GCs estradiol synthesis. (A) miR-214-3p binding site within NR5A1 3'UTR predicted by RNAhybrid; (B) target site of miR-214-3p within porcine NR5A1 mRNA 3'UTR and mutational site of NR5A1 3'UTR; (C) Dual luciferase assay via co-transfection of miR-214-3p agomir and wild-type vectors or mutant vectors - relative luciferase activity represented by RLUC/FLUC; (D) Relative NR5A1mRNA expression levels after treatment with miR-214-3p agomir; (E) Relative NR5A1 mRNA 
expression levels after treatment with miR-214-3p antagomir; $(F)$ Western blot analysis of NR5A1 protein expression after treatment with miR-214-3p agomir; $(\mathrm{H})$ Western blot analysis of NR5A1 protein expression after treatment with miR-214-3p antagomir; $(G, I)$ Quantification of NR5A1 protein levels. Note: Data are mean \pm SEM of three independent experiments; ${ }^{*} p<0.05,{ }^{* *} p<0.01$.

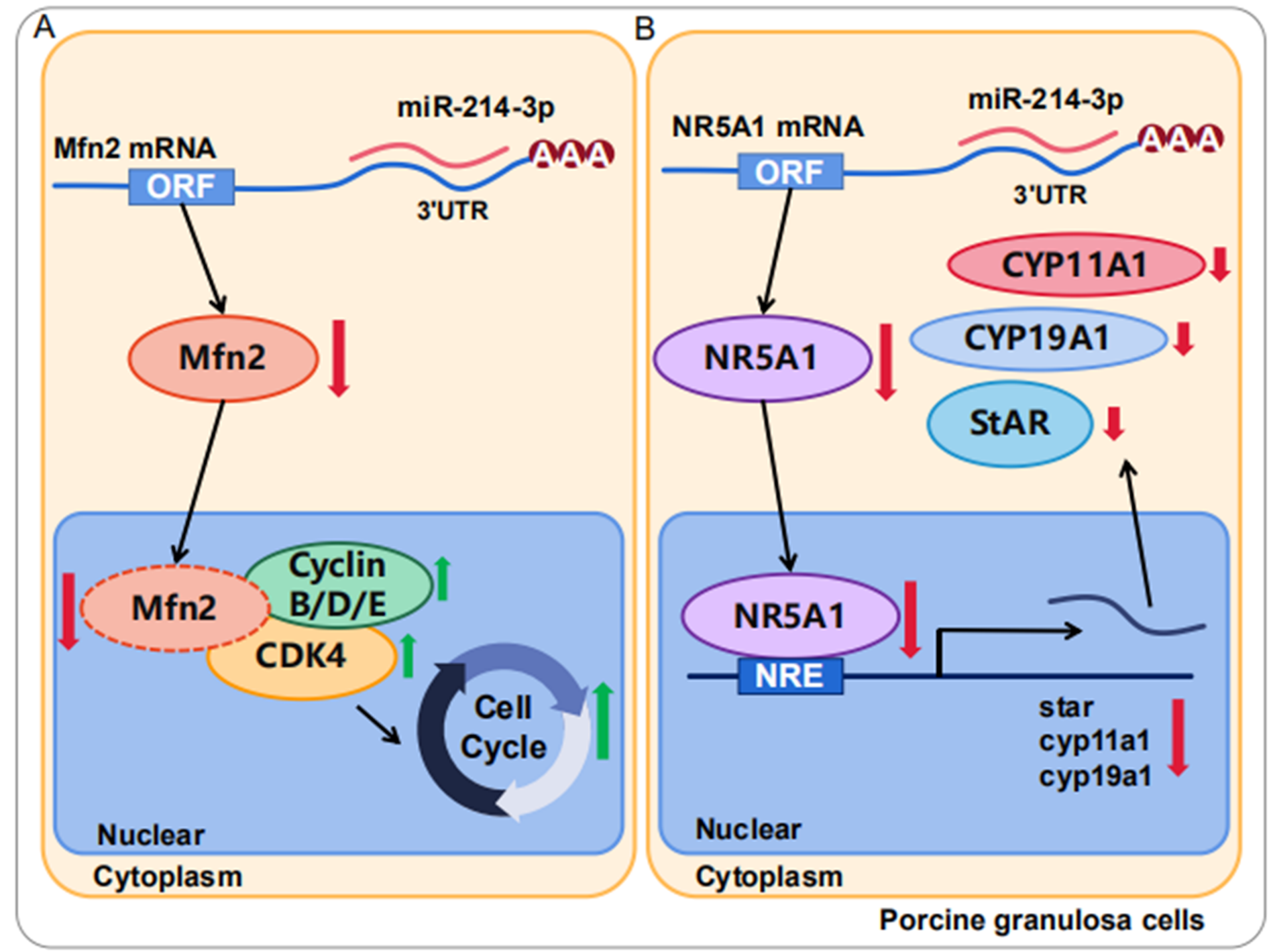

Figure 8

Schematic diagram of miR-214-3p regulation on porcine GCs proliferation and estradiol synthesis. (A) MiR-214-3p promotes porcine GCs proliferation by targeting Mfn2. (B) MiR-214-3p inhibits GCs estradiol synthesis by targeting NR5A1. Note: Green upward arrows indicate promotion of a given process; red downward arrows indicate that this process is inhibited.

\section{Supplementary Files}

This is a list of supplementary files associated with this preprint. Click to download. 
- Table1Primersequencesusedinthisstudy.pdf

Page 25/25 